\title{
Variants in the Toll-interacting protein gene are associated with susceptibility to sepsis in the Chinese Han population
}

\author{
Zhenju Song, Jun Yin, Chenling Yao, Zhan Sun, Mian Shao, Yaping Zhang, Zhengang Tao, Peizhi Huang,
} Chaoyang Tong*

\begin{abstract}
Introduction: Deregulated or excessive host immune responses contribute to the pathogenesis of sepsis. Toll-like receptor (TLR) signaling pathways and their negative regulators play a pivotal role in the modulation of host immune responses and the development of sepsis. The objective of this study was to investigate the association of variants in the TLR signaling pathway genes and their negative regulator genes with susceptibility to sepsis in the Chinese Han population.

Methods: Patients with severe sepsis $(n=378)$ and healthy control subjects $(n=390)$ were enrolled. Five genes, namely TLR2, TLR4, TLR9, MyD88 and TOLLIP, were investigated for their association with sepsis susceptibility by a tag single nucleotide polymorphism (SNP) strategy. Twelve tag SNPs were selected based on the data of Chinese Han in Beijing from the HapMap project and genotyped by direct sequencing. The mRNA expression levels of TOLLIP were determined using real-time quantitative Polymerase Chain Reaction (PCR) assays, and concentrations of tumor necrosis factor alpha (TNF- $\alpha$ ) and interleukin-6 (IL-6) were measured by enzyme-linked immunosorbent assay (ELISA).
\end{abstract}

Results: Our results showed that the minor C-allele of rs5743867 in TOLLIP was significantly associated with the decreased risk of sepsis $\left(P_{a d j}=0.00062\right.$, odds ratio $(\mathrm{OR})_{a d j}=0.71,95 \%$ confidence interval $(\mathrm{Cl}) 0.59$ to 0.86 ) after adjustment for covariates in multiple logistic regression analysis. A 3-SNP haplotype block harboring the associated SNP rs5743867 also displayed strong association with omnibus test $P$ value of 0.00049 . Haplotype GTC showed a protective role against sepsis $\left(P_{\text {adj }}=0.0012\right)$, while haplotype GCT showed an increased risk for sepsis $\left(P_{\text {adj }}=\right.$ 0.00092). After exposure to lipopolysaccharide (LPS), TOLLIP mRNA expression levels in peripheral blood mononuclear cells (PBMCs) from homozygotes for the rs5743867C allele were significantly higher than in heterozygotes and homozygotes for the rs5743867T allele ( $P=0.013$ and $P=0.01$, respectively). Moreover, the concentrations of TNF- $\alpha$ and IL- 6 in culture supernatants were significantly lower in the subjects of rs5743867CC genotype than in $C T$ and $\Pi$ genotype subjects $(P=0.016$ and $P=0.003$ for TNF- $\alpha ; P=0.01$ and $P=0.002$ for IL-6, respectively).

Conclusions: Our findings indicated that the variants in TOLLIP were significantly associated with sepsis susceptibility in the Chinese Han population.

\section{Introduction}

Despite continuous progress in the development of antibiotics and other supportive care therapies, sepsis remains an unconquered challenge for clinicians and

\footnotetext{
* Correspondence: tong.chaoyang@zs-hospital.sh.cn

Department of Emergency Medicine, Zhongshan Hospital, Fudan University, 180 Fenglin Road, Shanghai 200032, PR China
}

has an unacceptably high mortality rate of $30 \%$ to $50 \%$ for severe sepsis and septic shock [1,2]. The pathophysiology of sepsis involves highly complex interactions between invading microorganisms, the innate and adaptive immune systems of the host, and multiple downstream events leading to organ dysfunction [3]. Numerous studies have suggested that individuals vary
C Biomed Central

(c) 2011 Song et al.; licensee BioMed Central Ltd. This is an open access article distributed under the terms of the Creative Commons Attribution License (http://creativecommons.org/licenses/by/2.0), which permits unrestricted use, distribution, and reproduction in any medium, provided the original work is properly cited. 
in their responses to infection [4]. Currently, more and more evidence shows that common genetic variants of the innate and adaptive immune response pathway genes play an important role in determining the susceptibility to and outcome of sepsis [5-10].

Toll-like receptors (TLRs), a family of immune receptors, were recently reported to be involved in the recognition of pathogen-associated molecular patterns and the initiation of host immune responses [11]. In humans, more than 10 functional TLRs have been identified [12]. Among them, TLR2, TLR4, and TLR9 have been established to play a key role in the mediation of systemic responses to invading pathogens during sepsis $[11,12]$. After recognition of their respective ligands, TLRs induce inflammatory reactions by the activation of signaling pathways mediated by the adapter proteins myeloid differentiation factor 88 (MyD88) and Toll/ interleukin-1 (IL-1)-receptor domain-containing adapter-inducing interferon [12]. The immune response initiated by TLRs is an important mechanism of defense against pathogenic microorganisms. However, prolonged and excessive activation of TLR signaling pathways contributes to the pathogenesis of sepsis and organ injury. TLR signaling and subsequent functions, therefore, must be under tight negative regulation to maintain immune response balance [13]. Recent studies have indicated that several negative regulators of TLR signaling pathways, including Toll-interacting protein (TOLLIP), inhibited TLR signaling pathway-mediated inflammatory responses and restored immune system balance. Inadequate production of these endogenous negative regulators may also contribute to the pathogenesis of sepsis [14].

Several single-nucleotide polymorphisms (SNPs) in the TLR signaling pathway genes have been reported to influence the production of inflammatory cytokines and be associated with susceptibility to inflammatory diseases [15]. In studies focusing on infection or sepsis, associations have been described for SNPs in the TLR1 (rs5743551), TLR2 (rs5743708), TLR4 (rs4986790 and rs4986791), TLR9 (rs5743836), IRAK1 (rs1059703), and TIRAP genes (rs8177374 and rs7932766) [7,16-21]. However, no studies have addressed the impact of genetic variants in TLR signaling pathways and negative regulators on sepsis susceptibility in the Chinese Han population.

Therefore, given the pivotal role of TLR signaling pathways and their negative regulators in the development of sepsis, we hypothesized that variants in genes encoding components of the TLR signaling pathways and their negative regulators might confer susceptibility to sepsis. To test this hypothesis, we conducted a case control study using a tag SNP approach to investigate the association of variants in TLR2, TLR4, TLR9,
MyD88, and TOLLIP with susceptibility to sepsis in the Chinese Han population. In addition, we performed functional evaluation of the associated SNP.

\section{Materials and methods \\ Study design and enrollment}

The diagnosis of sepsis met the criteria recommended by the American College of Chest Physicians and the Society of Critical Care Medicine Consensus Conference [22]. Severe sepsis was defined as sepsis in combination with sepsis-induced acute organ dysfunction in at least one organ. Acute organ dysfunction was defined as Sequential Organ Failure Assessment (SOFA) scores of more than 2 for the organ in question. The SOFA score was calculated daily. Clinical and demographic data at baseline, including Acute Physiology and Chronic Health Evaluation (APACHE) II scores, previous health status, source of infection, microbiology, and intensive care unit mortality, were obtained after the patient met severe sepsis criteria. Exclusion criteria included age below 18 years, pregnancy, severe chronic respiratory disease, severe chronic liver disease (defined as a ChildPugh score of greater than 10), malignancy, use of highdose immunosuppressive therapy, and AIDS. Sex- and age-matched controls were selected from healthy blood donors. Healthy controls were defined as individuals without any recent acute illness, any chronic illness, or a history of sepsis. To reduce the potential confounding from ethnic backgrounds, only the Han Chinese population was enrolled in this study. The study was approved by the ethics committee of Zhongshan Hospital of Fudan University (Shanghai, China) (record number 2006-23). Informed consent was obtained from subjects or from their legal surrogates before enrollment.

\section{Single-nucleotide polymorphism selection and genotyping}

A total of five candidate genes involved in TLR signaling pathways and their negative regulators were selected on the basis of known biological activity: TLR2, TLR4, TLR9, MyD88, and TOLLIP. Tag SNPs were selected on the basis of the data of the Chinese Han in Beijing (CHB) from the HapMap project phase II [23]. Tag SNPs for each of the genes were selected separately. In total, 12 tag SNPs in the five genes were selected by Tagger within Haploview using the following tagging criteria: pairwise tagging of the HapMap population with $r^{2}$ of at least 0.8 and a minor allele frequency (MAF) of at least 5\%. Location and characterization of all of the tested SNPs are listed in Table 1.

Genomic DNA was extracted from whole blood with a FlexiGene DNA Kit (Qiagen, Hilden, Germany) in accordance with the protocol of the manufacturer. Genotyping was performed by direct sequencing. 
Table 1 Characteristics of the genotyped single-nucleotide polymorphisms in the genes of Toll-like receptor signaling pathways and negative regulators

\begin{tabular}{|c|c|c|c|c|c|c|}
\hline Gene & Location & SNP & SNP type & Major/minor allele & MAF & HWE $P$ value \\
\hline \multirow[t]{2}{*}{ TLR2 } & $4 q 32$ & rs1898830 & Tag SNP, intron & $A / G$ & 0.45 & 0.35 \\
\hline & & rs3804099 & Tag SNP, exon & $\mathrm{T} / \mathrm{C}$ & 0.32 & 0.64 \\
\hline \multirow[t]{3}{*}{$T L R 4$} & $9 q 32-q 33$ & rs2149356 & Tag SNP, intron & $\mathrm{G} / \mathrm{T}$ & 0.39 & 0.76 \\
\hline & & rs11536879 & Tag SNP, intron & $A / G$ & 0.16 & 0.47 \\
\hline & & rs1927907 & Tag SNP, intron & $\mathrm{C} / \mathrm{T}$ & 0.24 & 1.00 \\
\hline TLR9 & $3 p 21.3$ & rs352140 & Tag SNP, exon & $\mathrm{G} / \mathrm{A}$ & 0.38 & 1.00 \\
\hline \multirow[t]{2}{*}{ MyD88 } & $3 p 22$ & rs7744 & Tag SNP, 3' UTR & $A / G$ & 0.38 & 0.41 \\
\hline & & rs6853 & Tag SNP, 3' UTR & $A / G$ & 0.01 & 1.00 \\
\hline \multirow[t]{8}{*}{ TOLLIP } & $11 \mathrm{p} 15.5$ & rs3750920 & Tag SNP, exon & $\mathrm{G} / \mathrm{A}$ & 0.28 & 0.57 \\
\hline & & rs5743867 & Tag SNP, intron & $\mathrm{T} / \mathrm{C}$ & 0.35 & 0.61 \\
\hline & & rs3793964 & Tag SNP, intron & $\mathrm{A} / \mathrm{G}$ & 0.37 & 0.07 \\
\hline & & rs3793963 & Intron & $\mathrm{G} / \mathrm{A}$ & 0.25 & 0.30 \\
\hline & & rs5744002 & Intron & $\mathrm{G} / \mathrm{A}$ & 0.33 & 1.00 \\
\hline & & rs5743942 & Tag SNP, intron & $\mathrm{T} / \mathrm{C}$ & 0.12 & 1.00 \\
\hline & & rs5743944 & Intron & $\mathrm{G} / \mathrm{A}$ & 0.26 & 0.87 \\
\hline & & rs5743947 & Intron & $\mathrm{G} / \mathrm{A}$ & 0.31 & 0.53 \\
\hline
\end{tabular}

HWE, Hardy-Weinberg equilibrium; MAF, minor allele frequency; MyD88, myeloid differentiation factor 88; SNP, single-nucleotide polymorphism; TLR, Toll-like receptor; TOLLIP, Toll-interacting protein; UTR, untranslated region.

The sequencing reactions were performed with Applied Biosystems BigDye (version 3.1) chemistry (Applied Biosystems, Foster City, CA, USA), and the sequences were resolved with an ABI 3730 Genetic Analyzer. The primers and polymerase chain reaction (PCR) protocols used are shown in Table S1 in Additional file 1. Analyses of the sequence traces were performed with the Staden package and double-scored by a second operator.

\section{Isolation and stimulation of cells from healthy subjects} Peripheral blood mononuclear cells (PBMCs) were derived from healthy subjects by means of the Ficoll gradient density centrifugation method. Isolated PBMCs were plated at a density of $1 \times 10^{6}$ cells per milliliter in 24-well plates and cultured in RPMI 1640 medium with $10 \%$ fetal bovine saline at $37^{\circ} \mathrm{C}$ with $5 \% \mathrm{CO}_{2}$. The cells were incubated for 6 hours in the presence or absence of $100 \mathrm{ng} / \mathrm{mL}$ Escherichia coli 0111:B4 lipopolysaccharide (LPS) (Sigma-Aldrich, St. Louis, MO, USA). After incubation, supernatants and cell pellets were harvested and stored at $-80^{\circ} \mathrm{C}$ until use.

\section{RNA purification and TOLLIP mRNA expression analysis} Total RNA was extracted with an RNeasy Mini kit (Qiagen). One hundred nanograms of RNA was used for cDNA synthesis with a High-Capacity cDNA Reverse Transcription Kit (Applied Biosystems) in accordance with the protocol of the manufacturer. The synthesized cDNA was used for real-time PCR performed by SYBR green-based assay on an ABI 7900HT system (Applied Biosystems). The primers for the TOLLIP gene were forward 5'-CGGTGTACATCGGTGAGC-3' and reverse
5'-CGTCTCGTACACCGCGTAG-3'. The primers for the endogenous control gene glyceraldehyde-3-phosphate dehydrogenase (GAPDH) were forward 5'AAGGTCG GAGTCAACGGATT-3' and reverse 5'CTCCTGGAA GATGGTGATGG-3'. We carried out initial denaturation at $95^{\circ} \mathrm{C}$ for 10 seconds followed by 40 cycles of PCR $\left(95^{\circ} \mathrm{C}\right.$ for 5 seconds, $57^{\circ} \mathrm{C}$ for $30 \mathrm{sec}-$ onds, and $72^{\circ} \mathrm{C}$ for 30 seconds). TOLLIP mRNA expression levels were normalized to the levels of GAPDH. All experiments were run in triplicate. Independent cDNA synthesis was carried out twice.

\section{Measurement of tumor necrosis factor-alpha and interleukin-6 levels}

Concentrations of tumor necrosis factor-alpha (TNF- $\alpha$ ) and IL- 6 in culture supernatants were measured with a human enzyme-linked immunosorbent assay (ELISA) kit (R\&D Systems, Inc., Minneapolis, MN, USA) in accordance with the protocol of the manufacturer.

\section{Statistical analysis}

The demographic variables between different groups were compared by chi-square test for categorical variables. The genotype data were analyzed for deviations from Hardy-Weinberg equilibrium by the Haploview version 4.1 software [24]. The differences of allele and genotype distributions between the sepsis and healthy control groups were compared with the chi-square test or Fisher's exact test when appropriate. $P$ values for genotypic distributions were calculated with the global genotype test. Allele frequencies of cases and controls were used to calculate the odds ratio (OR) and the 95\% 
confidence interval (CI). Multivariate logistic regression was used to adjust for potential confounding factors, including age and gender. Block was determined by Haploview version 4.1 with a linkage disequilibrium (LD)-based partitioning algorithm [25]. The data of the observed blocks were analyzed with the omnibus test and haplotype-specific association statistics ( $\mathrm{T}$ test) as implemented in PLINK [26]. The case/control omnibus test was an $\mathrm{H}-1$ degree of freedom test, in which $\mathrm{H}$ was the number of different haplotypes. The Bonferroni method was used to correct for multiple comparisons where applicable. A two-tailed $P$ value of less than 0.05 was considered statistically significant, whereas a value of corrected $P$ of less than $(0.05$ divided by the number of tests) was considered significant after Bonferroni correction. Differences in relative mRNA expression and TNF- $\alpha$ and IL- 6 levels between genotypes were evaluated by one-way analysis of variance (ANOVA). When a significant difference was obtained in ANOVA, post hoc comparison with the least significant difference test was used to identify specific group differences. The software used for statistical calculations was the SPSS 15.0 (SPSS, Inc., Chicago, IL, USA) unless specified otherwise.

\section{Results}

\section{Characteristics of the study population}

From February 2006 to November 2009, 378 patients with severe sepsis were enrolled in this case control study. An additional population of 390 ethnicitymatched healthy volunteers was recruited for comparison. The baseline characteristics and clinical data of all subjects are shown in Table 2. The mean ages were 64.1 years for patients with severe sepsis and 65.8 years for healthy controls $(P>0.05)$. The proportions of males were $58.2 \%$ in patients with severe sepsis and $57.9 \%$ in healthy controls $(P>0.05)$. The primary sources of infection were the lungs (85.4\%), followed by abdomen $(6.1 \%)$, blood stream (3.2\%), urinary tract $(2.9 \%)$, and others $(2.4 \%)$. The overall 30 -day mortality rate of patients with severe sepsis was $32.3 \%$.

\section{Association analyses of TLR2, TLR4, TLR9, MyD88, and TOLLIP polymorphisms with susceptibility to sepsis} All of the 12 tag SNPs were genotyped successfully by direct sequencing. Four other SNPs located in the intron region of TOLLIP (rs3793963, rs5744002, rs5743944, and rs5743947) were identified in the process of sequencing (Table 1). The genotyping success rates ranged from $97.5 \%$ to $99 \%$, and all of the genotype distributions were consistent with Hardy-Weinberg equilibrium $(P>0.05)$ (Table 1). The allele and genotype distributions of these SNPs in healthy controls and patients with sepsis are listed in Table 3 and in Table S2 in Additional file 1. When patients with sepsis were compared with healthy
Table 2 Demographic and clinical characteristics of the study subjects

\begin{tabular}{|c|c|c|}
\hline & Healthy controls & Patients with sepsis \\
\hline Number & 390 & 378 \\
\hline Age, years & $65.8 \pm 12.2$ & $64.1 \pm 12.6$ \\
\hline Males/Females & $226 / 164$ & $220 / 158$ \\
\hline APACHE \| score & NA & $18.3 \pm 4.3$ \\
\hline Survival & NA & $67.7 \%$ \\
\hline Length of ICU stay, days & NA & $18.6 \pm 5.6$ \\
\hline Diabetes & NA & $39(10.3 \%)$ \\
\hline Chronic liver disease & NA & $12(3.2 \%)$ \\
\hline Chronic renal failure & NA & $16(4.2 \%)$ \\
\hline Congestive heart failure & NA & $23(6.1 \%)$ \\
\hline Chronic pulmonary disease & NA & $31(8.2 \%)$ \\
\hline \multicolumn{3}{|l|}{ Sepsis insult } \\
\hline Lung & NA & $323(85.4 \%)$ \\
\hline Abdomen & NA & $23(6.1 \%)$ \\
\hline Bloodstream & NA & $12(3.2 \%)$ \\
\hline Urinary tract infection & NA & $11(2.9 \%)$ \\
\hline Others & NA & $9(2.4 \%)$ \\
\hline Microbiology positive & NA & $159(42.1 \%)$ \\
\hline Gram-positive & NA & $61(38.4 \%)$ \\
\hline Gram-negative & NA & 65 (40.9\%) \\
\hline Fungi & NA & $15(9.4 \%)$ \\
\hline Mixed & NA & $18(11.3 \%)$ \\
\hline Microbiology unknown & NA & $219(57.9 \%)$ \\
\hline
\end{tabular}

APACHE II, Acute Physiology and Chronic Health Evaluation II; ICU, intensive care unit; NA, not applicable.

controls, two tag SNPs in TOLLIP were observed in association with sepsis susceptibility. The minor allele $\mathrm{C}$ of rs5743867 in TOLLIP was associated with a decreased risk of sepsis $(P=0.00016, \mathrm{OR}=0.67,95 \%$ CI 0.54 to 0.82 ), and the significance remained present after Bonferroni correction ( $P=0.0026$ corrected for 16 SNPs tested). Furthermore, in multivariate logistic analyses adjusting for age and gender, the rs574386 C allele was still significantly associated with protection from sepsis $\left(P_{\mathrm{adj}}=\right.$ $0.00062, \mathrm{OR}_{\mathrm{adj}}=0.71,95 \% \mathrm{CI} 0.59$ to 0.86$)$. The genotype distribution of rs5743867 was also significantly different between sepsis and control groups $(P=0.001)$, and the difference remained significant after adjustment for age and gender in multiple logistic regression analysis $\left(P_{\text {adj }}=\right.$ $0.0018)$ and for multiple comparisons $(P=0.016$ corrected for 16 SNPs tested). SNP rs5743942 of TOLLIP also showed an association with sepsis susceptibility. The $\mathrm{C}$ allele of rs5743942 was associated with increased risk of sepsis $\left(P_{\mathrm{adj}}=0.034, \mathrm{OR}_{\mathrm{adj}}=1.40,95 \%\right.$ CI 1.03 to 1.88$)$. Also, the genotype distribution was significantly different between sepsis and control groups $\left(P_{\text {adj }}=0.016\right)$. However, the difference was not significant after Bonferroni correction $(P>0.05$ corrected for 16 SNPs tested). Both allele and genotype distributions of the other 14 SNPs in 
Table 3 Association analysis of the eight single-nucleotide polymorphisms in TOLLIP between sepsis patients and healthy control subjects

\begin{tabular}{|c|c|c|c|c|c|c|c|c|}
\hline \multirow[b]{2}{*}{ SNP } & \multirow[b]{2}{*}{ Control } & \multirow[b]{2}{*}{ Sepsis } & \multicolumn{4}{|c|}{ Allelic comparison } & \multicolumn{2}{|c|}{ Genotypic comparison } \\
\hline & & & $P$ & $P_{\text {adj }}$ & OR $(95 \% \mathrm{Cl})$ & $\mathrm{OR}_{\text {adj }}(95 \% \mathrm{Cl})$ & $P$ & $P_{\text {adj }}$ \\
\hline \multicolumn{9}{|c|}{ rs3750920 } \\
\hline AA & $29(7.5 \%)$ & $26(7.0 \%)$ & & & & & & \\
\hline$A G$ & 159 (41.3\%) & 160 (43.1\%) & & & & & & \\
\hline GG & $197(51.2 \%)$ & 185 (49.9\%) & 0.867 & 0.972 & $1.02(0.82-1.27)$ & $1.01(0.72-1.38)$ & 0.867 & 0.911 \\
\hline \multicolumn{9}{|c|}{ rs5743867 } \\
\hline CC & $64(16.6 \%)$ & $32(8.6 \%)$ & & & & & & \\
\hline$C T$ & $176(45.7 \%)$ & $161(43.3 \%)$ & & & & & & \\
\hline$\pi$ & $145(37.7 \%)$ & 179 (48.1\%) & 0.00016 & 0.00062 & $0.67(0.54-0.82)$ & $0.71(0.59-0.86)$ & 0.001 & 0.0018 \\
\hline \multicolumn{9}{|c|}{ rs3793964 } \\
\hline GG & 39 (10.2\%) & $41(11.1 \%)$ & & & & & & \\
\hline$A G$ & $196(51.0 \%)$ & $210(56.6 \%)$ & & & & & & \\
\hline AA & 149 (38.8\%) & $120(32.3 \%)$ & 0.140 & 0.251 & $1.17(0.95-1.44)$ & $1.09(0.82-1.39)$ & 0.179 & 0.280 \\
\hline \multicolumn{9}{|c|}{ rs3793963 } \\
\hline AA & $18(4.7 \%)$ & $22(5.9 \%)$ & & & & & & \\
\hline$A G$ & $151(39.4 \%)$ & 145 (39.1\%) & & & & & & \\
\hline GG & $214(55.9 \%)$ & $204(55.0 \%)$ & 0.635 & 0.664 & $1.06(0.84-1.37)$ & $1.04(0.81-1.29)$ & 0.752 & 0.794 \\
\hline \multicolumn{9}{|c|}{ rs5744002 } \\
\hline AA & $42(10.9 \%)$ & $35(9.5 \%)$ & & & & & & \\
\hline$A G$ & $161(41.9 \%)$ & 175 (47.4\%) & & & & & & \\
\hline GG & $181(47.2 \%)$ & 159 (43.1\%) & 0.591 & 0.694 & $1.06(0.86-1.32)$ & $1.02(0.84-1.26)$ & 0.752 & 0.810 \\
\hline \multicolumn{9}{|c|}{ rs5743942 } \\
\hline$C C$ & $6(1.6 \%)$ & $4(1.1 \%)$ & & & & & & \\
\hline$C T$ & 65 (16.8\%) & 95 (25.5\%) & & & & & & \\
\hline$\pi$ & $315(81.6 \%)$ & 274 (73.4\%) & 0.021 & 0.034 & $1.45(1.06-1.98)$ & $1.40(1.03-1.88)$ & 0.013 & 0.016 \\
\hline \multicolumn{9}{|c|}{ rs5743944 } \\
\hline AA & 19 (4.9\%) & $32(8.7 \%)$ & & & & & & \\
\hline$A G$ & 156 (40.5\%) & 131 (35.4\%) & & & & & & \\
\hline GG & $210(54.6 \%)$ & 207 (55.9\%) & 0.607 & 0.642 & $1.06(0.84-1.34)$ & $1.03(0.81-1.30)$ & 0.074 & 0.102 \\
\hline \multicolumn{9}{|c|}{ rs5743947 } \\
\hline AA & $33(8.6 \%)$ & 34 (9.2\%) & & & & & & \\
\hline$A G$ & 157 (41.0\%) & 177 (47.8\%) & & & & & & \\
\hline GG & 193 (50.4\%) & 159 (43.0\%) & 0.094 & 0.302 & $1.21(0.97-1.50)$ & $1.05(0.85-1.31)$ & 0.118 & 0.231 \\
\hline
\end{tabular}

Data are presented as number (percentage) of subjects. $P$ was determined using the chi-square test. $P$ value adjusted for age and gender $\left(P_{\text {adj }}\right)$ came from multivariate logistic regression. A $P$ value of less than $0.003(0.05 / 16)$ was considered statistically significant after Bonferroni correction. Rs5743867 remained significant after Bonferroni correction. $\mathrm{Cl}$, confidence interval; OR, odds ratio; $\mathrm{OR}_{\text {adj, }}$ odds ratio adjusted for age and gender; SNP, single-nucleotide polymorphism; TOLLIP, Toll-interacting protein.

TLR2, TLR4, TLR9, MyD88, and TOLLIP did not vary significantly between sepsis patients and healthy controls (Table S2 in Additional file 1). Because TLRs detect specific microbial components, we performed the association analyses of TLR2 and TLR9 with Gram-positive sepsis patients and TLR4 and TLR9 with Gram-negative sepsis patients. However, no significant difference was found (Tables S3 and S4 in Additional file 1).

\section{Association analyses of TOLLIP, TLR2, TLR4, TLR9, and MyD88 haplotypes with susceptibility to sepsis}

We then performed haplotype analysis to investigate whether the haplotypes in the five genes were associated with sepsis risk. Two haplotype blocks in the TOLLIP region were determined by Haploview with an LD-based partitioning algorithm (Figure 1). Block 1 contained four SNPs (rs5744002, rs3793963, rs3793964, and rs3750920) spanning $8 \mathrm{~kb}$ on the upstream region of TOLLIP, which generated three common haplotypes with a frequency of greater than 5\%: GGAG, AAGA, and GGGG. In the global test, haplotypes in this block were not significantly associated with sepsis risk $\left(P_{\text {adj }}=0.244\right)$. The haplotype GGAG in this block was associated with decreased risk of sepsis with borderline significance $\left(P_{\text {adj }}=0.041\right)$ (Table 4$)$ but the association was not significant after correction for multiple testing. Block 2 


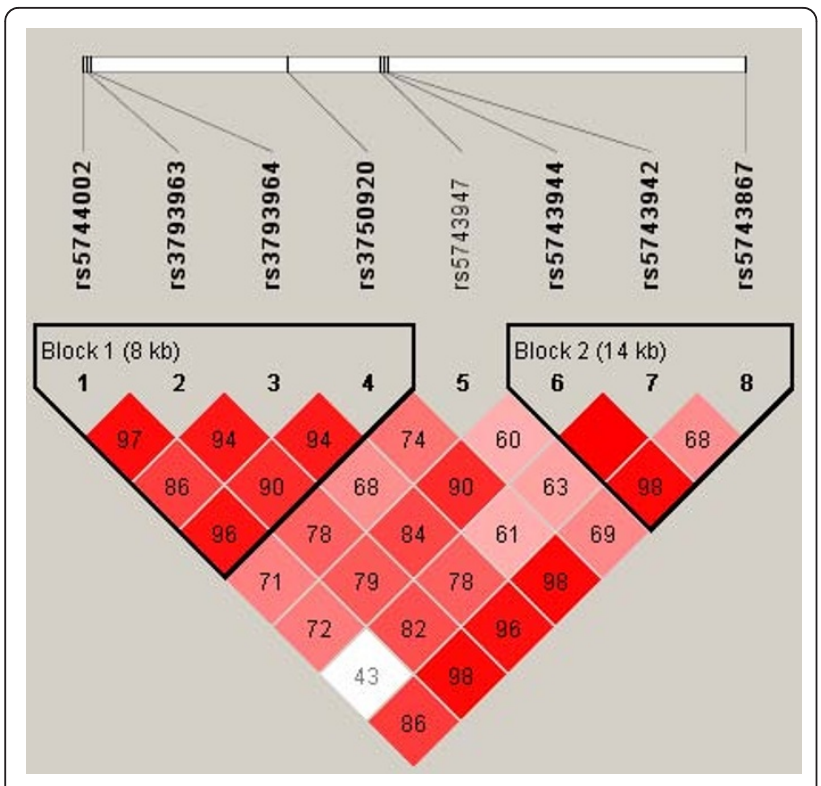

Figure 1 Linkage disequilibrium (LD) plot of eight singlenucleotide polymorphisms in Toll-interacting protein (TOLLIP) genotyped in this study. The plot was constructed with the Haploview program [24], and $r^{2}(\times 100)$ values are depicted in the diamonds. Blocks were determined by Haploview with an LD-based partitioning algorithm [25]. The LD color scheme was stratified according to the logarithm of the odds (LOD) score and D': white, $\mathrm{D}^{\prime}=1$ and $\mathrm{LOD}$ score $=2$; pink or light red, $\mathrm{D}^{\prime}=1$ and $\mathrm{LOD}$ score $\geq 2$; and bright red, $\mathrm{D}^{\prime}=1$ and $\mathrm{LOD}$ score $\geq 2$.

harbored three SNPs (rs5743944, rs5743942 and rs5743867) spanning $14 \mathrm{~kb}$ on the downstream region of TOLLIP, which generated four haplotypes with a frequency of greater than 5\%: GTC, GTT, ATT, and GCT. A global test showed a significant difference between sepsis and control groups, with a $P_{\text {adj }}$ value of 0.00049 . Among these haplotypes, the haplotype GTC appeared protective and the frequency in the sepsis group was lower than in the healthy control group $\left(P_{\text {adj }}=0.0012\right.$,
$\mathrm{OR}_{\mathrm{adj}}=0.73,95 \%$ CI 0.62 to 0.89 ) (Table 4). Another haplotype, GCT, was significantly associated with increased risk of sepsis, and carriers of the GCT haplotype had a 1.62 -fold increased risk for sepsis $\left(P_{\text {adj }}=\right.$ 0.00092). No haplotypes in TLR2, TRL4, TLR9, and $M y D 88$ were associated with sepsis risk in this study (data not shown).

\section{Association analyses of TOLLIP mRNA expression level with rs5743867 genotypes}

We then evaluated the association between rs5743867 genotype and TOLLIP mRNA expression to determine whether the above SNP association reflected cis-acting regulatory effects on TOLLIP. A total of 38 healthy subjects were enrolled to determine the amount of TOLLIP mRNA expression level: 6 subjects with rs5743867CC genotype, 18 subjects with rs5743867CT genotype, and 14 subjects with rs5743867TT genotype. As shown in Figure 2, no significant difference in TOLLIP mRNA expression was observed among $\mathrm{CC}, \mathrm{CT}$, and TT genotypes in the unstimulated PBMCs $(P>0.05)$. After stimulation with LPS for 6 hours, the TOLLIP mRNA expression in PBMCs was significantly higher in CC homozygotes compared with both CT heterozygotes and TT homozygotes $(P=0.013$ and $P=0.01$, respectively), whereas the difference between the CT and TT groups was not statistically significant $(P=0.779)$.

\section{Association analyses of tumor necrosis factor-alpha and interleukin-6 levels with rs5743867 genotypes}

Because TOLLIP is involved in the cytokine processing, we also evaluated whether the variant influences TNF- $\alpha$ and IL-6 production (Figure 3). We observed a significant association between TNF- $\alpha$ and IL- 6 levels and rs5743867 genotypes under the LPS-stimulated condition. Subjects with homozygotes for the rs5743867C allele were associated with lower levels of TNF- $\alpha$ and

Table 4 Associations between TOLLIP haplotypes and sepsis susceptibility

\begin{tabular}{|c|c|c|c|c|c|c|c|}
\hline \multirow[b]{2}{*}{ LD block } & \multirow[b]{2}{*}{ Haplotype $^{a}$} & \multicolumn{2}{|c|}{ Frequency } & \multirow[b]{2}{*}{$P$ value } & \multirow[b]{2}{*}{$P_{\text {adj }}$ value } & \multirow[b]{2}{*}{ OR $(95 \% \mathrm{CI})$} & \multirow[b]{2}{*}{$\mathrm{OR}_{\mathrm{adj}}(95 \% \mathrm{Cl})$} \\
\hline & & Healthy control & Sepsis & & & & \\
\hline \multirow[t]{4}{*}{ Block $1^{\text {b }}$} & Global test & & & 0.127 & 0.244 & & \\
\hline & GGAG & 0.615 & 0.558 & 0.027 & 0.041 & $0.79(0.65-0.97)$ & $0.86(0.72-0.98)$ \\
\hline & AAGA & 0.225 & 0.215 & 0.636 & 0.768 & $0.94(0.74-1.20)$ & $0.98(0.80-1.44)$ \\
\hline & GGGG & 0.060 & 0.083 & 0.088 & 0.177 & $1.41(0.95-2.10)$ & $1.03(0.80-2.32)$ \\
\hline \multirow[t]{5}{*}{ Block $2^{c}$} & Global test & & & 0.00018 & 0.00049 & & \\
\hline & GTC & 0.380 & 0.299 & 0.00085 & 0.0012 & $0.69(0.56-0.86)$ & $0.73(0.62-0.89)$ \\
\hline & $\mathrm{GTT}$ & 0.283 & 0.302 & 0.399 & 0.424 & $1.10(0.88-1.38)$ & $1.06(0.80-1.34)$ \\
\hline & $\mathrm{ATT}$ & 0.248 & 0.261 & 0.590 & 0.778 & $1.07(0.85-1.35)$ & $1.02(0.79-1.32)$ \\
\hline & $\mathrm{GCT}$ & 0.076 & 0.134 & 0.00028 & 0.00092 & $1.87(1.33-2.63)$ & $1.62(1.27-2.86)$ \\
\hline
\end{tabular}

A $P$ value of less than $0.013(0.05 / 4)$ was considered statistically significant after Bonferroni correction. Haplotype GTC and GCT in block 2 remained significant after Bonferroni correction. ${ }^{a}$ Haplotype frequencies of less than $5 \%$ were not included in the analyses; ${ }^{b}$ the order of polymorphisms was rs 5744002 , rs 3793963 , rs3793964, and rs3750920; 'the order of polymorphisms was rs5743944, rs5743942, and rs5743867. Cl, confidence interval; LD, linkage disequilibrium; OR, odds ratio; $\mathrm{OR}_{\mathrm{adj}}$, odds ratio adjusted for age and gender; $P_{\mathrm{adj}}, P$ value adjusted for age and gender; TOLLIP, Toll-interacting protein. 
IL-6 compared with heterozygotes and homozygotes for the rs5743867T allele after LPS stimulation $(P=0.016$ and $P=0.003$ for TNF- $\alpha ; P=0.01$ and $P=0.002$ for IL-6, respectively). However, no significant association was observed between TNF- $\alpha$ and IL- 6 levels and rs5743867 genotype under the unstimulated condition $(P>0.05)$.

\section{Discussion}

This was the first report on genetic association analysis of TLR signaling pathways and their negative regulatory genes in Chinese Han patients with sepsis. Sixteen SNPs in five genes were successfully genotyped in this study. Our results showed that a tag SNP rs5743867 in TOLLIP, which influences the expression of TOLLIP mRNA and the production of TNF- $\alpha$ and IL- 6 , was significantly associated with susceptibility to sepsis. Consistent with the single SNP analyses, a three-SNP haplotype block harboring the associated SNP rs5743867 was also associated with the risk of sepsis.

The TLR signaling pathways and their negative regulators play a critical role in the pathogenesis of sepsis. Although several variants in the TLR signaling pathway genes have been implicated in susceptibility to sepsis and infectious diseases [7,16-20], the effect of variants in the negative regulatory genes of TLR signaling pathways on sepsis susceptibility has never been reported. We demonstrated here the first evidence for an association of sepsis susceptibility with variants in TOLLIP. TOLLIP, a negative regulator affecting cytoplasmic signal transduction, is widely expressed in a variety of human tissues. The inhibitory action of TOLLIP is mediated via suppression of autophosphorylation and kinase activity of IL-1 receptorassociated kinase 1 , which is an important mediator in the TLR signal transduction [27]. Transfection of TOL$L I P$ in intestinal epithelial cells resulted in decreased

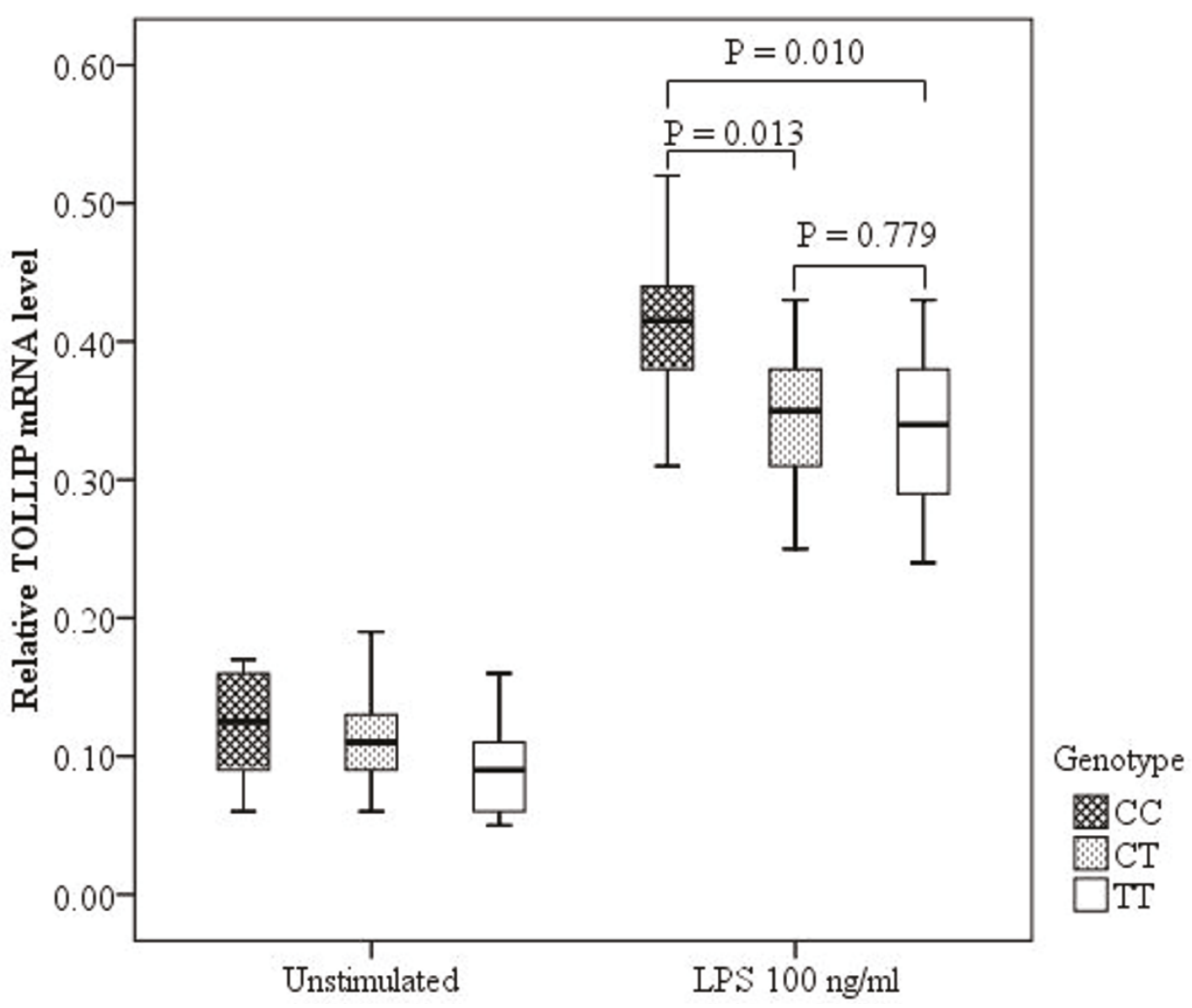

Figure 2 Association results between Toll-interacting protein (TOLLIP) gene expression levels and rs5743867 genotypes. Expression levels of TOLLIP in peripheral blood mononuclear cells were normalized with glyceraldehyde-3-phosphate dehydrogenase (GAPDH) expression and are presented as the median, interquartile range, and extremes. The mRNA expression levels of TOLLIP were significantly different among CC, $C T$, and $\Pi$ genotypes under the lipopolysaccharide (LPS)-stimulated condition ( $P=0.023$, analysis of variance). No significant difference in TOLLIP mRNA expression levels was observed among CC, $C T$, and $\Pi$ genotypes under the unstimulated condition ( $P=0.156$, analysis of variance). 
responsiveness to stimulation with LPS and lipoteichoic acid. Moreover, the production of inflammatory cytokines in TOLLIP-deficient mice, in comparison with that of wild-type mice, was significantly reduced [28].

The in vitro expression assays of mRNA and production of TNF- $\alpha$ and IL- 6 in PBMCs under the LPS-stimulated condition clarified the functional relevance of SNP rs5743867 in TOLLIP. Subjects who were homozygotes with the $\mathrm{C}$ allele had higher mRNA expression of $T O L-$ LIP and lower levels of TNF- $\alpha$ and IL-6. These results indicated that SNP rs5743867 influenced the expression of TOLLIP and subsequently decreased the production of inflammatory cytokines. Rs5743867 is located in the intron region of TOLLIP. This is in accordance with the recent findings from genome-wide association studies that most of the associated variants of complex diseases are located outside the coding regions [29]. However, it is currently unclear how an intronic polymorphism can induce a phenotypic change. Rs5743867 may induce exon skipping, enhance the use of cryptic splice sites, or alter the ratio of alternatively spliced isoforms. Additionally, rs5743867 is more likely a marker in LD with a regulatory region polymorphism that controls expression levels of TOLLIP or a functional coding region SNP that influences the biological effect of TOLLIP. Exhaustive resequencing is needed to find or rule out the possibility of an as-yet-unidentified causal SNP in LD with rs5743867, and further functional evaluation of novel or associated SNPs is also needed.
To our knowledge, only two reports in the literature have described associations between TOLLIP variants and human diseases. Schimming and colleagues [30] demonstrated that the -526G/C (rs5743854) polymorphism in the promoter region of TOLLIP is significantly associated with the susceptibility of atopic dermatitis, which is a common inflammatory skin disorder. However, the mRNA expression of TOLLIP in lymphoid cells was not significantly different between the genotypes of rs5743854 [30]. Another study, conducted in 2008 by Wurfel and colleagues [7], screened SNPs in 43 TLRrelated genes and identified one SNP (rs5743856) in TOLLIP affecting TLR-mediated inflammatory response. However, no study about the association between this functional polymorphism and sepsis susceptibility was reported. In our study, these two polymorphisms were not genotyped, because they were not included in the HapMap CHB data. Future study of TOLLIP should consider these functional variants.

Our results also indicated that tag SNPs of TLR2, TLR4, TLR9, and MyD88 did not represent major risk factors for sepsis development. Two nonsynonymous TLR4 SNPs (rs4986790 and rs4986791) have been shown to be associated with sepsis and infectious diseases in Caucasians and Africans. In another project (data not shown here), we observed that rs4986790 and rs4986791 are absent in Han Chinese populations, and this finding is in agreement with reports from other Asian populations $[19,31,32]$. Until now, no other SNPs
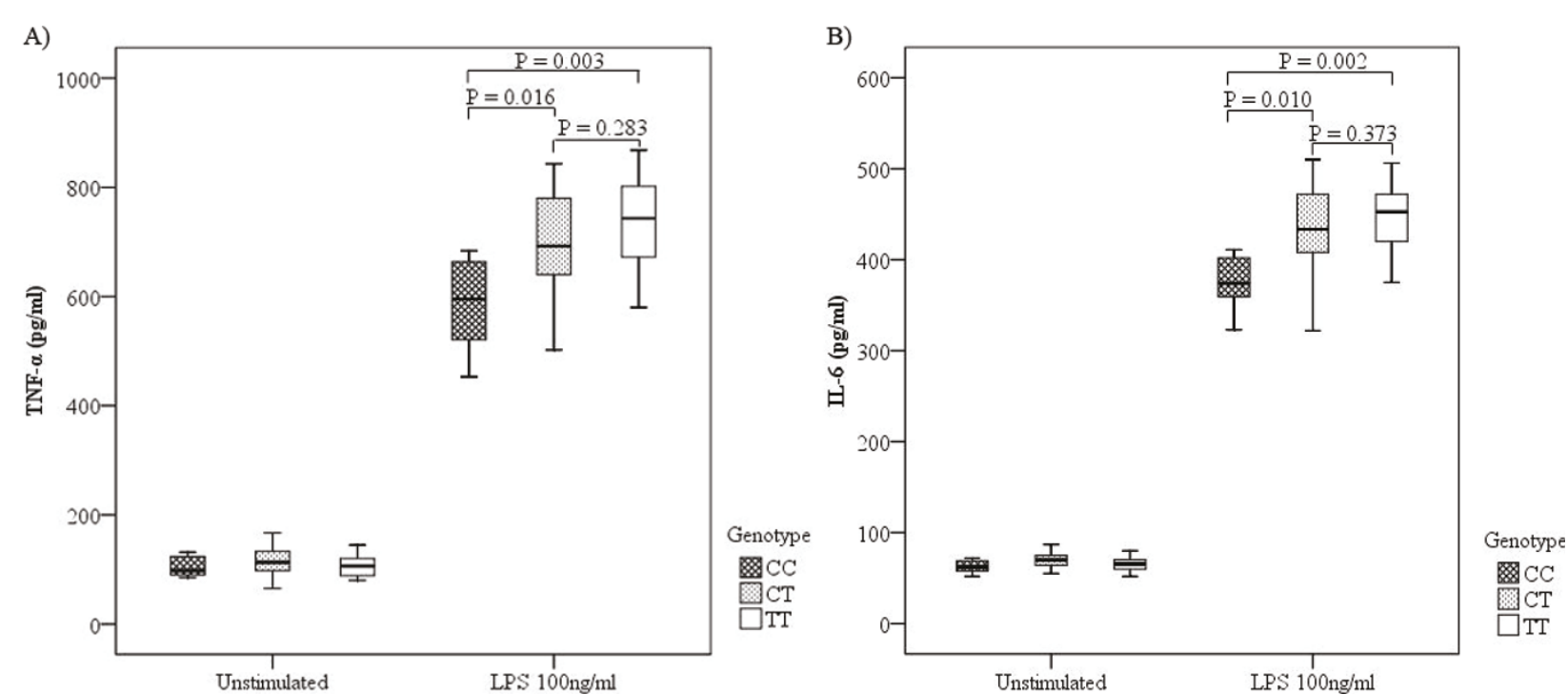

Figure 3 Association results between tumor necrosis factor-alpha (TNF- $\alpha$ ) and interleukin-6 (IL-6) levels and rs5743867 genotypes. Concentrations of TNF- $\alpha$ and IL- 6 in culture supernatants are presented as the median, interquartile range, and extremes. The TNF- $\alpha$ and IL- 6 levels were significantly different among CC, CT, and TT genotypes under the lipopolysaccharide (LPS)-stimulated condition $(P=0.01, P=0.012$, analysis of variance). No significant difference in TNF- $\alpha$ and IL-6 levels was observed among CC, CT, and TT genotypes under the unstimulated condition ( $P=0.528, P=0.209$, analysis of variance). 
or haplotypes of TLR4 were found to be associated with the susceptibility of sepsis or infectious diseases among Asian populations. It was reported that polymorphisms in TLR2 and TLR9 were associated with tuberculosis and other infectious diseases in previous studies; however, no association with sepsis susceptibility was found in our study [33,34]. One reason for these inconsistencies could be explained by the fact that the spectrum of infectious pathogens in our study was different from that of previous studies.

There were several limitations in our study. First, the association needs to be replicated in independent studies. Further replication studies in other populations are also expected. Second, we did not re-sequence the gene and instead used publicly available SNP databases. Thus, some variants could have been missed because of the incompleteness of these databases. Additionally, we did not evaluate whether the expression levels of TOLLIP are different between septic and non-septic patients.

\section{Conclusions}

In our study, genetic and expression evidence indicated that a tag SNP in the intron region of TOLLIP was associated with sepsis susceptibility in the Chinese Han population by influencing the expression levels. These data supported the concept that genetic variation in the negative regulators of TLR signaling pathways plays an important role in the development of sepsis. Of note, whether the genetic variation is associated with sepsis susceptibility in other populations still needs to be explored.

\section{Key messages}

- Individuals carrying the T allele of rs5743867 and haplotype GCT in Toll-interacting protein (TOLLIP) gene have a higher risk of developing sepsis in the Chinese Han population.

- Single-nucleotide polymorphism (SNP) rs5743867 influences the expression of TOLLIP mRNA and the production of tumor necrosis factor-alpha and interleukin-6.

- Tag SNPs of TLR2, TLR4, TLR9, and MyD88 are not associated with sepsis susceptibility in the Chinese Han population.

\section{Additional material}

Additional file 1: Supplementary data. A word document containing the following tables: Table S1: Primers and PCR protocols for SNPS genotyping; Table S2: Allele and genotype frequencies of TLR2, TLR4, TLR9 and MyD88 in the study subjects; Table S3: Allele and genotype frequencies of TLR2 and TLR9 in the gram-positive sepsis patients and healthy controls; Table S4: Allele and genotype frequencies of TLR4 and TLR9 in the gram-negative sepsis patients and healthy controls.

\section{Abbreviations}

ANOVA: analysis of variance; CHB: Chinese Han in Beijing; Cl: confidence interval; GAPDH: glyceraldehyde-3-phosphate dehydrogenase; IL: interleukin; LD: linkage disequilibrium; LPS: lipopolysaccharide; MyD88: myeloid differentiation factor 88; OR: odds ratio; $O R_{\text {adj: }}$ odds ratio adjusted for age and gender; $P_{\text {adj: }} P$ value adjusted for age and gender; PBMC: peripheral blood mononuclear cell; PCR: polymerase chain reaction; SNP: singlenucleotide polymorphism; SOFA: Sequential Organ Failure Assessment; TLR: Toll-like receptor; TNF-a: tumor necrosis factor-alpha; TOLLIP: Toll-interacting protein.

\section{Acknowledgments}

We thank Jinjun Jiang, Qinjun Shen, Yong Zhang, Jin Zhang, Xinmei Yang, and Ruiyan Liu for patient recruitment; Lu Fan and Yu Hu for critical review of an earlier version of the manuscript; Xun Chu for assistance in data handling; and the patients and staff of the emergency and respiratory intensive care units at Zhongshan Hospital, Fudan University. This work was supported by the Shanghai Committee of Science and Technology (09411960400), the National Natural Science Foundation of China (81000023), and the Shanghai Public Health Fund for Distinguished Young Scholars (08GWQ026).

\section{Authors' contributions}

$C T$ headed the project and supervised and conducted the study. Z Song designed the study, carried out the statistical analysis, and drafted the manuscript. JY performed the data collection in the sepsis patient group and helped to conduct the experiments. CY, Z Sun, MS, YZ, and ZT were involved in the recruitment of the sepsis patients and healthy controls. $\mathrm{PH}$ participated in the study design and helped to draft the manuscript. All authors read and approved the final manuscript.

\section{Competing interests}

The authors declare that they have no competing interests.

Received: 6 July 2010 Revised: 8 October 2010

Accepted: 10 January 2011 Published: 10 January 2011

\section{References}

1. Cohen J: The immunopathogenesis of sepsis. Nature 2002, 420:885-891.

2. Martin GS, Mannino DM, Eaton S, Moss M: The epidemiology of sepsis in the United States from 1979 through 2000. N Engl J Med 2003, 348:1546-1554.

3. Hotchkiss RS, Karl IE: The pathophysiology and treatment of sepsis. N Engl J Med 2003, 348:138-150.

4. Lin MT, Albertson TE: Genomic polymorphisms in sepsis. Crit Care Med 2004, 32:569-579.

5. Flores C, Perez-Mendez L, Maca-Meyer N, Muriel A, Espinosa E, Blanco J, Sanguesa R, Muros M, Garcia JG, Villar J: A common haplotype of the LBP gene predisposes to severe sepsis. Crit Care Med 2009, 37:2759-2766.

6. Watanabe $\mathrm{E}$, Buchman TG, Hirasawa H, Zehnbauer BA: Association between lymphotoxin-alpha (tumor necrosis factor-beta) intron polymorphism and predisposition to severe sepsis is modified by gender and age. Crit Care Med 38:181-193.

7. Wurfel MM, Gordon AC, Holden TD, Radella F, Strout J, Kajikawa O, Ruzinski JT, Rona G, Black RA, Stratton S, Jarvik GP, Hajjar AM, Nickerson DA, Rieder M, Sevransky J, Maloney JP, Moss M, Martin G, Shanholtz C, Garcia JG, Gao L, Brower R, Barnes KC, Walley KR, Russell JA, Martin TR: Toll-like receptor 1 polymorphisms affect innate immune responses and outcomes in sepsis. Am J Respir Crit Care Med 2008, 178:710-720.

8. Huh JW, Song K, Yum JS, Hong SB, Lim CM, Koh Y: Association of mannose-binding lectin-2 genotype and serum levels with prognosis of sepsis. Crit Care 2009, 13:R176.

9. Arcaroli J, Fessler MB, Abraham E: Genetic polymorphisms and sepsis. Shock 2005, 24:300-312.

10. Henckaerts L, Nielsen KR, Steffensen R, Van Steen K, Mathieu C, Giulietti A Wouters PJ, Milants I, Vanhorebeek I, Langouche L, Vermeire S, Rutgeerts P, Thiel S, Wilmer A, Hansen TK, Van den Berghe G: Polymorphisms in innate 
immunity genes predispose to bacteremia and death in the medical intensive care unit. Crit Care Med 2009, 37:192-201, e191-193.

11. Akira S, Takeda K, Kaisho T: Toll-like receptors: critical proteins linking innate and acquired immunity. Nat Immunol 2001, 2:675-680.

12. Leulier F, Lemaitre B: Toll-like receptors-taking an evolutionary approach. Nat Rev Genet 2008, 9:165-178.

13. Cook DN, Pisetsky DS, Schwartz DA: Toll-like receptors in the pathogenesis of human disease. Nat Immunol 2004, 5:975-979.

14. Shibolet O, Podolsky DK: TLRs in the Gut. IV. Negative regulation of Tolllike receptors and intestinal homeostasis: addition by subtraction. Am J Physiol Gastrointest Liver Physiol 2007, 292:G1469-1473.

15. Schroder NW, Schumann RR: Single nucleotide polymorphisms of Toll-like receptors and susceptibility to infectious disease. Lancet Infect Dis 2005, 5:156-164

16. Khor CC, Chapman SJ, Vannberg FO, Dunne A, Murphy C, Ling EY, Frodsham AJ, Walley AJ, Kyrieleis O, Khan A, Aucan C, Segal S, Moore CE, Knox K, Campbell SJ, Lienhardt C, Scott A, Aaby P, Sow OY, Grignani RT, Sillah J, Sirugo G, Peshu N, Williams TN, Maitland K, Davies RJ, Kwiatkowski DP, Day NP, Yala D, Crook DW, et al: A Mal functional variant is associated with protection against invasive pneumococcal disease, bacteremia, malaria and tuberculosis. Nat Genet 2007, 39:523-528.

17. Hawn TR, Dunstan SJ, Thwaites GE, Simmons CP, Thuong NT, Lan NT, Quy HT, Chau TT, Hieu NT, Rodrigues S, Janer M, Zhao LP, Hien TT, Farrar JJ, Aderem A: A polymorphism in Toll-interleukin 1 receptor domain containing adaptor protein is associated with susceptibility to meningeal tuberculosis. J Infect Dis 2006, 194:1127-1134.

18. Holmes $C L$, Russell JA, Walley KR: Genetic polymorphisms in sepsis and septic shock: role in prognosis and potential for therapy. Chest 2003, 124:1103-1115.

19. Ferwerda B, McCall MB, Alonso S, Giamarellos-Bourboulis EJ, Mouktaroudi M, Izagirre N, Syafruddin D, Kibiki G, Cristea T, Hijmans A, Hamann L, Israel S, ElGhazali G, Troye-Blomberg M, Kumpf O, Maiga B, Dolo A, Doumbo O, Hermsen CC, Stalenhoef AF, van Crevel R, Brunner HG, Oh DY, Schumann RR, de la Rua C, Sauerwein R, Kullberg BJ, van der Ven AJ, van der Meer JW, Netea MG: TLR4 polymorphisms, infectious diseases, and evolutionary pressure during migration of modern humans. Proc Natl Acad Sci USA 2007, 104:16645-16650.

20. Velez DR, Wejse C, Stryjewski ME, Abbate E, Hulme WF, Myers JL, Estevan R, Patillo SG, Olesen R, Tacconelli A, Sirugo G, Gilbert JR, Hamilton CD, Scott WK: Variants in toll-like receptors 2 and 9 influence susceptibility to pulmonary tuberculosis in Caucasians, African-Americans, and West Africans. Hum Genet 2010, 127:65-73.

21. Kumpf O, Giamarellos-Bourboulis EJ, Koch A, Hamann L, Mouktaroudi M, Oh DY, Latz E, Lorenz E, Schwartz DA, Ferwerda B, Routsi C, Skalioti C, Kullberg BJ, van der Meer JW, Schlag PM, Netea MG, Zacharowski K, Schumann RR: Influence of genetic variations in TLR4 and TIRAP/Mal on the course of sepsis and pneumonia and cytokine release: an observational study in three cohorts. Crit Care 14:R103.

22. Levy MM, Fink MP, Marshall JC, Abraham E, Angus D, Cook D, Cohen J, Opal SM, Vincent JL, Ramsay G: 2001 SCCM/ESICM/ACCP/ATS/SIS International Sepsis Definitions Conference. Crit Care Med 2003, 31:1250-1256

23. A haplotype map of the human genome. Nature 2005, 437:1299-1320

24. Barrett JC, Fry B, Maller J, Daly MJ: Haploview: analysis and visualization of LD and haplotype maps. Bioinformatics 2005, 21:263-265.

25. Gabriel SB, Schaffner SF, Nguyen H, Moore JM, Roy J, Blumenstiel B, Higgins J, DeFelice M, Lochner A, Faggart M, Liu-Cordero SN, Rotimi C, Adeyemo A, Cooper R, Ward R, Lander ES, Daly MJ, Altshuler D: The structure of haplotype blocks in the human genome. Science 2002, 296:2225-2229.

26. Purcell S, Neale B, Todd-Brown K, Thomas L, Ferreira MA, Bender D, Maller J, Sklar P, de Bakker PI, Daly MJ, Sham PC: PLINK: a tool set for wholegenome association and population-based linkage analyses. Am J Hum Genet 2007, 81:559-575.

27. Zhang G, Ghosh S: Negative regulation of toll-like receptor-mediated signaling by Tollip. J Biol Chem 2002, 277:7059-7065.

28. Didierlaurent A, Brissoni B, Velin D, Aebi N, Tardivel A, Kaslin E, Sirard JC, Angelov G, Tschopp J, Burns K: Tollip regulates proinflammatory responses to interleukin-1 and lipopolysaccharide. Mol Cell Biol 2006, 26:735-742.
29. Scott LJ, Mohlke KL, Bonnycastle LL, Willer CJ, Li Y, Duren WL, Erdos MR, Stringham HM, Chines PS, Jackson AU, Prokunina-Olsson L, Ding CJ, Swift AJ, Narisu N, Hu T, Pruim R, Xiao R, Li XY, Conneely KN, Riebow NL, Sprau AG, Tong M, White PP, Hetrick KN, Barnhart MW, Bark CW, Goldstein JL, Watkins L, Xiang F, Saramies J, et al: A genome-wide association study of type 2 diabetes in Finns detects multiple susceptibility variants. Science 2007, 316:1341-1345.

30. Schimming TT, Parwez Q, Petrasch-Parwez E, Nothnagel M, Epplen JT, Hoffjan S: Association of toll-interacting protein gene polymorphisms with atopic dermatitis. BMC Dermatol 2007, 7:3.

31. Wu MS, Cheng TY, Shun CT, Lin MT, Chen LC, Lin JT: Functional polymorphisms of CD14 and toll-like receptor 4 in Taiwanese Chinese with Helicobacter pylori-related gastric malignancies. Hepatogastroenterology 2006, 53:807-810.

32. Nakada TA, Hirasawa H, Oda S, Shiga H, Matsuda K, Nakamura M, Watanabe E, Abe R, Hatano M, Tokuhisa T: Influence of toll-like receptor 4, CD14, tumor necrosis factor, and interleukine-10 gene polymorphisms on clinical outcome in Japanese critically ill patients. J Surg Res 2005, 129:322-328.

33. Caws M, Thwaites G, Dunstan S, Hawn TR, Lan NT, Thuong NT, Stepniewska K, Huyen MN, Bang ND, Loc TH, Gagneux S, van Soolingen D, Kremer K, van der Sande M, Small P, Anh PT, Chinh NT, Quy HT, Duyen NT, Tho DQ, Hieu NT, Torok E, Hien TT, Dung NH, Nhu NT, Duy PM, van Vinh Chau N, Farrar J: The influence of host and bacterial genotype on the development of disseminated disease with Mycobacterium tuberculosis. PLoS Pathog 2008, 4:e1000034.

34. Ng MT, van 't Hof R, Crockett JC, Hope ME, Berry S, Thomson J, McLean MH, McColl KE, El-Omar EM, Hold GL: Increase in NF-\{kappa\}B binding affinity of the $C$ allelic variant of the Toll-like receptor 9 -1237T/ $C$ polymorphism is associated with Helicobacter pylori induced gastric disease. Infect Immun 2009.

doi:10.1186/cc9413

Cite this article as: Song et al: Variants in the Toll-interacting protein gene are associated with susceptibility to sepsis in the Chinese Han population. Critical Care 2011 15:R12.

\section{Submit your next manuscript to BioMed Central and take full advantage of:}

- Convenient online submission

- Thorough peer review

- No space constraints or color figure charges

- Immediate publication on acceptance

- Inclusion in PubMed, CAS, Scopus and Google Scholar

- Research which is freely available for redistribution

Submit your manuscript at www.biomedcentral.com/submit
Ciomed Central 